\title{
A (RE)CONSTRUÇÃO DE IDENTIDADES DO SER AMERICANO MODERNO E A CRIAÇÃO SIMBÓLICA DE ARTURO USLAR PIETRI: DIÁLOGOS ENTRE LITERATURA E HISTÓRIA
}

\section{THE (RE) CONSTRUCTION OF AMERICAN MODERN BEING IDENTITIES AND THE SYMBOLIC CREATION OF ARTURO USLAR PIETRI: DIALOGUES BETWEEN LITERATURE AND HISTORY}

\author{
Gisele Reinaldo da SILVA*
}

Resumo: Este trabalho busca refletir sobre o papel do novo romance histórico contemporâneo, no tocante à (re)construção de identidades do ser americano moderno, tomando por base a obra El Camino de El Dorado do escritor venezuelano Arturo Uslar Pietri (1947). Ao reportar-se ao período da Conquista Espanhola da América, embalada pela força do Rio Amazonas, Uslar Pietri empreende uma viagem simbólica sobre a história da civilização do mundo ocidental, rumo à descoberta do puramente local, inserido no universal. O autor implica-se, no contexto da literatura Hispano-Americana do século XX, na busca por uma identidade individual e coletiva que melhor contribuísse à compreensão histórico-cultural de seu país, a Venezuela e, mais amplamente, do indivíduo americano. Será necessário, ainda, para o desenvolvimento deste trabalho, o embasamento na vasta obra ensaística do autor (1949, 1955, 1969, 1991).

Palavras-chave: Arturo Uslar Pietri. Romance Histórico. Identidades latino-americanas.

Abstract: This paper aims to reflect about the role of the new historical romance contemporary, regarding the (re) construction of modern American identities, based on the work El Camino de El Dorado, from the Venezuelan writer Arturo Uslar Pietri (1947). When referring to the period of the Spanish Conquest of America, guided by the force of the Amazon River, Uslar Pietri embarks on a symbolic journey into the civilization history $\mathrm{o}$ in the Western world, towards the discovery of purely local, inserted into the universal. The author implies himself, in the context of Spanish-American literature of the twentieth century, seeking an individual and collective identity that best contribute to the historical and cultural understanding of his country, Venezuela and, more broadly, the American individual identity. It will be also necessary for the development of this paper, the essayistic wide basis in the author's work (1949, 1955, 1969, 1991).

Keywords: Arturo Uslar Pietri. Historical Romance. Latin American Identities.

$$
\begin{array}{r}
\text { "O essencial é saber ver, } \\
\text { Saber ver sem pensar, } \\
\text { Saber ver quando se vê } \\
\text { E nem pensar quando se vê } \\
\text { Nem ver quando se pensa. }
\end{array}
$$

Mas isso (tristes de nós que trazemos a alma vestida!) Isso exige um estudo profundo,

\footnotetext{
* Doutoranda bolsista CNPq em Literaturas Hispânicas pelo Programa de Pós-graduação em Letras Neolatinas da Universidade Federal do Rio de Janeiro, UFRJ. E-mail: giselere@gmail.com
} 
Uma aprendizagem de desaprender". Fernando Pessoa (1974)

O escritor e filósofo espanhol Agapito Maestre, em sua Introdução a Ensayos sobre el Nuevo Mundo, antologia de textos políticos de Arturo Uslar Pietri (2002), afirma que o trato que o escritor recebeu nas últimas décadas, próximas a sua morte, se referia a este como uma figura já histórica, passada, embora com reconhecimento reverente a seu legado. Poucos são os que se atrevem a avaliar suas verdadeiras contribuições à literatura, ao pensamento e ao periodismo, nos dias atuais. Isso porque o excelente curriculum vitae do autor, paradoxalmente, acabou por propagar mais tópicos sobre o personagem público que configurou, ao invés de enfocar na densa obra de um grande romancista e pensador do século XX.

Sua longa carreira, marcada por infindos prêmios e aplausos, deixou em segundo plano a realidade de que, nascido em 1906, com data de publicação de seu primeiro grande romance, Las lanzas coloradas, em 1931, já o encontramos, em 1936, como presidente da Associação de Escritores da Venezuela. Em 1939, é nomeado Ministro da Educação no governo de Medina Angaria e, a partir de então, poderíamos seguir citando diversos prêmios ao longo de sua carreira, até, por exemplo, 1990, quando recebe o Premio Príncipe de Asturias das Letras por ser, segundo o jurado, o criador do romance histórico moderno na América Hispânica ou ainda, em 1991, quando se converte no primeiro venezuelano a receber o Prêmio Internacional de Romance Rómullo Gallegos. Engajou-se, simultaneamente, na diplomacia, cultura, política e escritura. Ademais do já mencionado cargo de Ministro da Educação da Venezuela, assumiu, posteriormente, o de Interior, mais tarde, o da Fazenda, desempenhando engajamento singular em sua tarefa de diplomata, jornalista, romancista e ensaísta.

Além de sua importância como artista e político, Uslar Pietri foi, enquanto homem das Letras, um dos máximos expoentes do realismo mágico, como Miguel Ángel Asturias, sintetizando tal corrente estética e literária como o "redescobrimento da mestiçagem hispano-americana". No entanto, seus comentaristas tendem a silenciar sua obra, em função de ressaltar o personagem político e enfatizam, por exemplo, sua grande influência no debate político e intelectual de seu país, no seio da UNESCO, como embaixador da Venezuela, esquecendo as contribuições de Uslar Pietri na compreensão da América Hispânica para além dos nacionalismos localistas, ou ainda, sua especial forma de estudar a cultura hispano-americana como polo chave da civilização ocidental. 
Há, ainda, os que fazem especial enfoque aos cargos públicos que ostentou, sua oposição às ditaduras de Gómez e Pérez Jiménez, bem como sua candidatura à Presidência da República da Venezuela, em 1963, esquecendo seu pensamento de caráter liberal e democrático. Enaltecem, ainda, o fato de o escritor venezuelano ter sido diretor do diário El Nacional, de Caracas, e que sua fama, como articulista e divulgador cultural na televisão de seu país, jamais foi alcançada por outro intelectual, mas não sinalizam que este trabalho jornalístico esteve pautado por uma potente convicção ilustrada acerca da cultura como liberação da humanidade.

Os esquecimentos são, portanto, uma constante quando se trata de Arturo Uslar Pietri. Há uma tendência a não enfatizar suas contribuições à cultura venezuelana, no tocante, por exemplo, à repercussão que tiveram as revistas Válvula e El Ingenioso Hidalgo, fundadas a partir de seu regresso da Europa, junto com Julián Padrón, Alfredo Boulton e Pedro Sotillo, as quais representaram, em 1936, as vanguardas que dinamizaram a cultura venezuelana. O legado e a adoção do Surrealismo europeu na América não somente o fez romper com a literatura do modernismo decadente, como também tornou parte de sua obra considerada vanguarda até hoje. Sua obra é poligráfica. Abarca contos, romances, teatro, poesia e ensaios de ampla temática: política, econômica, histórica, artística, crítica e literária. Seu legado torna-o, indubitavelmente, um dos maiores humanistas do século XX.

Não obstante, as críticas a Arturo Uslar Pietri se dividem em reconhecimento excessivo e indiferença parcial. Interessa-nos, enquanto campo de pesquisa, a parte da indiferença, quanto ao que esteve por trás de todo seu brilho público, impulsionando-o a construir uma literatura novedosa. É como se o magistério de Uslar Pietri, bem como seu engajamento com o político e o social, mais que estimulá-lo à criação literária, se tivesse convertido em uma carga. Isso porque seu espírito abarcador do humanista latino-americano, em uma época de bárbaros especialistas, não foi bem visto. A presença do poeta na vida pública justificava-se por sua crença de que "a obra é inseparável da vida".

Para o autor, sua obra, que é vida, ou sua vida, que é obra, ensinava/ensina da maneira mais válida o entender e cumprir os deveres de seu tempo, como lição aberta para o entendimento e cumprimento dos nossos na contemporaneidade. Filho de militar e neto de Juan Pietri, vice-presidente do caudilho Juan Vicente Gómez, não poderia renunciar a seu destino político, que no caso de muitos escritores seria um fator exclusivamente relevante para a compreensão de sua personalidade e obra, mas que, no 
caso de Uslar Pietri, acaba configurando mais uma barreira que uma plataforma para aproximarmo-nos de suas verdadeiras contribuições à história da cultura HispanoAmericana em geral ou à história do pensamento particular.

Sua obra literária e ensaística, que adquire unidade através de uma singular reconstrução, não deve ser ignorada perante sua maestria em outros campos de participação social. Arturo Uslar Pietri compreende e põe em prática o espírito transcultural apontado pelo escritor e crítico literário uruguaio Ángel Rama (2008), em sua obra Transculturación narrativa en América Latina, tanto nos seus ideais como no seu modo de fazer literatura, a qual abstém-se de um afã puramente internacionalista para dar lugar à peculiaridade cultural desenvolvida no interior da Venezuela e da América Latina, de modo mais amplo.

Esta originalidade só poderia ser alcançada mediante a representatividade da região na qual surgia a expressão literária, em função da notoriedade desta sociedade em comparação às "progenitoras", tanto pela diferença do meio físico, quanto pela composição étnica heterogênea, além do distinto grau de desenvolvimento a respeito do que se visualizava como único modelo de progresso: o europeu. A missão patriótica de Uslar Pietri tornou sua literatura instrumento apropriado para fraguar a nacionalidade. $\mathrm{O}$ princípio ético do escritor se aproximou ao sentimento nacional de modo a tornar os assuntos nativos sua "matéria-prima". Rama (1998) compara, nesta conjuntura, o escritor latino-americano ao agricultor ou o operário na cadeia de produção.

Trata-se da nova linguagem latino-americana como instrumento de independência. Abstendo-se de uma possível redução da obra literária à mera documentação sociológica, Uslar Pietri engaja-se no questionamento central de sua época, conforme a definição de Rama:

\begin{abstract}
Reestabelecer as obras literárias dentro das operações culturais que cumprem as sociedades americanas, reconhecendo suas audazes construções significativas e o ingente esforço por manejar autenticamente as linguagens simbólicas desenvolvidas pelos homens americanos, é um modo de reforçar estes vertebrais conceitos de independência, originalidade e representatividade. As obras literárias não estão fora das culturas, e sim, as coroam e na medida em que estas culturas são invenções seculares e multitudinárias fazem do escritor um produtor que trabalha com as obras de inumeráveis homens. Um compilador, teria dito Roa Bastos. O genial tecelão, no vasto ateliê histórico da sociedade americana ${ }^{1}$ (RAMA, 2008, p. 24).
\end{abstract}

Ao criticar obras literárias provenientes, pura e simplesmente, de barcos europeus, Rama (2008) alude à necessidade de que o nome da América Latina não seja evocado em vão, ressaltando a importância de que a acumulação cultural interna seja 
capaz de prover não somente a "matéria-prima" indispensável, como também uma cosmovisão, uma língua, uma técnica para produção das obras literárias. Trata-se de um esforço de descolonização espiritual de um continente cuja marca inventiva é fértil e a luta por constituir-se como uma das ricas fontes culturais do universo é pertinente, em uma era cuja maré está a favor de uma internacionalização culturalmente presunçosa.

O processo de transculturação como um processo de aquisição de uma nova cultura (aculturação), em concomitância com um processo de desarraigo parcial da cultura precedente (desculturação), em paralelo à criação de novos fenômenos culturais (neoculturação) reflete bem a realidade da América Latina, a qual nunca configurou uma entidade passiva, receptora de uma nova cultura, sem nenhuma reação criadora. Ao contrário, a cultura presente na América Latina está composta, de acordo com Rama (2008), de valores idiossincráticos, os quais estão em vigor desde tempos remotos, ao mesmo tempo em que está composta de uma energia criadora em constante evolução e mobilidade. Em outras palavras, a comunidade latino-americana é, em grande parte, transculturada.

Trata-se de uma força comunitária que atua com desenvoltura, tanto sobre sua herança particular, segundo as situações próprias de seu desenvolvimento, como sobre as inovações culturais provenientes do estrangeiro. De acordo com Rama, é justamente esta capacidade latino-americana de elaborar com originalidade, ainda que em difíceis circunstancias históricas, toda esta mescla cultural o que a torna uma sociedade vida, criadora e plural (RAMA, 2008, p. 41).

\section{A chave para o El Dorado: o élan poético e revolucionário de Uslar Pietri transmudado às Letras}

Arturo Uslar Pietri, inserido neste contexto do século XX de anseio pela criação poética de uma literatura implicada no questionamento da realidade, afirma o seguinte, no tocante a sua obra:

Lo que puedan valer dentro de la literatura de mi tempo es cosa que yo difícilmente puedo juzgar, pero, en cambio, sé muy a ciencia que son para mí de una importancia extraordinaria, de una importancia tan extraordinaria como mi propia vida, porque, después de todo, y acaso en el sentido más valioso y verdadero, son mi propia vida, es decir, lo más propio, reconocible y duradero de ella (USLAR PIETRI, 1956, p. X).

De acordo com Uslar Pietri (1956), gêneros e formas são maneiras, ou vias de aproximação mais segura de desvelar o mais íntimo do ser humano, ao utilizar os gêneros e as formas como instrumentos, não como busca de verdades gerais e abstratas, 
pois esta não é a função da literatura. $\mathrm{O}$ escritor deve buscar na essência humana de cada ser a essência, também, de seus personagens. Conforme a assertiva do autor:

\begin{abstract}
Si el objeto del arte literario fuera el de encontrar y expresar verdades generales sobre ese ser abstracto que llamamos el hombre, toda la literatura estaría reducida a una especie de proceso de decantación cuyo resultado último sería la formación de un apotegma válido para todos los seres en todas las circunstancias. Toda la novela moderna parecería un dispendioso y caótico trabajo de verificación de la verdad contenida, por ejemplo, en una máxima de La Rochefoucauld, que acaso podría ser aquella que dice: "No siempre es por valor y por castidad que los hombres son valientes y que las mujeres son castas". Pero no es ese el fin de la literatura, ni de su inagotable y maravillosa búsqueda. Lo que le importa al escritor son los caracteres, las personas, las situaciones, las formas particulares y locales de los seres, de los sentimientos, de los conflictos. No es el amor en abstracto, sino el amor por Laura, en lo que tiene de único, que es precisamente lo que tiene de universal, según una de las paradojas fundamentales de la literatura; ni es tampoco la duda y la vacilación, sino la duda y la vacilación de un hombre que se llama Hamlet; ni el conflicto del sentimiento y la realidad, sino los conflictos de un ingenioso hidalgo que vivió, o vive verdaderamente, "en un lugar de la Mancha". (USLAR PIETRI, 1956, p. XII)
\end{abstract}

A primeira obra de Uslar Pietri, Barrabás y otros relatos, ao surgir no fim de 1928, buscava distanciar-se do formato de contos que vinham sendo escritos na Venezuela, até então. Seu objetivo era reagir ao costumbrismo, apresentando em seus personagens o conflito de um homem que participaria decisivamente, embora, a princípio, de forma inconsciente, no momento mais importante do processo de ruptura nas Letras ocidentais. Uslar Pietri ressalta seu afã de promover mudanças na literatura e na condição venezuelana, inspirado pela cena literária plena de convites à insurreição, condizente com um mundo em mudança.

Preocupava-se com a estagnação em que a Venezuela dos anos 20 se encontrava até o momento, compreendendo a necessidade de renovação, o que o leva, como ele mesmo salienta, a fazer vanguarda. Uslar Pietri advertia, ainda, para o fato de que não bastava discutir e proclamar havia a necessidade de se realizar uma obra que refletisse, em sua nova condição, a presença de uma nova consciência não só da literatura, mas também da condição do ser venezuelano. Seus livros de contos seguintes foram Red, em 1936, e Treinta Hombres y sus sombras, em 1949.

Uslar Pietri se propõe a essa esperançosa tarefa, guiado pelo propósito de avançar ao máximo, extrapolando a realidade local, de maneira a alcançar o universal, sem detrimento do nacional. Sua busca era pela representação do mais universal e válido, dentro do nacional. Seu primeiro romance, Las lanzas Coloradas, foi escrito em uma primavera de Paris, em 1931, embora o autor afirmasse, neste momento, o assédio das visões de seu país.

Nova Revista Amazônica | n. 4 | Jul./Dez. 2014 | 15-31

PPG Linguagens e Saberes da Amazônia, Bragança, Pará 
$\mathrm{O}$ autor entra pelo caminho da novela histórica porque pensava que, para expressar o nacional fora do mero paisagismo, fosse necessário começar por buscá-lo nas horas em que alcançou sua mais alta e reveladora tensão. O escritor sentia, por exemplo, que no impulso destrutor e criador da guerra da Independência, a condição crioula de nossa humanidade foi revelada de um modo pleno, e é este o enredo que conduzirá poeticamente os seres e sucessos desse primeiro romance. Sua intenção é expressar, em sua obra, a condição humana intrínseca ao homem venezuelano, que se assemelha com a de outros homens que compartilham seu destino histórico.

A literatura, conforme Uslar Pietri,

[...] como el arte entero, no es monólogo solitario, es diálogo vivo de dar y recibir. Cuando parece monólogo es porque la respuesta tarda y a veces no llega sino en una generación posterior. Pero ha de llegar para que la obra de arte se cumpla. Cada vez de una manera más consciente y clara he ido sintiendo lo que escribo como mi parte de un diálogo que me empeño en establecer con mi gente. Mi gente es toda la que tiene o es susceptible de tener conmigo cosas en común, comienza, en grado de parentesco decreciente, pero vivo y eficaz, por mi pueblo de venezolanos, para llegar hasta el más remoto de los hombres. Pero el más remoto de los hombres siempre será más importante para mí que el mero gozo estético de hacer frases (USLAR PIETRI, 1956, p. XIV).

Uslar Pietri, nascido no início do século XX (1906) e morto no início do XXI (2001), militou no melhor estoicismo hispânico, embora a dor e a paixão que sentiu por sua terra nunca tenham terminado em resignação, pois, recriou, através do redescobrimento da mestiçagem cultural, as melhores contribuições da cultura de língua espanhola ao debate das culturas universais. Foi um renovador imprescindível da narrativa hispano-americana, um observador inteligente e um ator comprometido com os tempos convulsos da Venezuela e de toda a América Latina.

Se considerarmos que descobrir o venezuelano, descobrir o essencial da América Hispânica foi a pretensão de Las lanzas coloradas, não é difícil imaginar que tudo o que veio posteriormente foi uma ampliação, um desenvolvimento, uma permanente matização deste grandioso descobrimento do puramente local, inserido no universal. Esta foi a principal busca de Uslar Pietri e seu decisivo legado: mostrar que a América Latina é um Mundo Novo, principal objetivo de seu primeiro romance, que poderia ser também o resumo de toda sua obra.

Romantizar e ensaiar a história da América Hispânica, como duas dimensões imprescindíveis da política, foram suas principais atividades. Expressar as múltiplas arestas da relação dos indivíduos com sua história foi algo mais que um objetivo de seu labor, foi uma obsessão. Para o autor, torna-se impossível, sem história, o encontro da 
identidade individual e coletiva. Porém, isso não significa que o homem da América Hispânica seja preso pelo determinismo histórico ou por algum tipo de tradicionalismo, pois, de forma alguma, o escritor adota um tom moralizante, ao contrário, vai descobrindo quase programaticamente o caráter mestiço do continente hispanoamericano.

Uslar Pietri romantiza a história e constrói uma ensaística que visa mostrar a essência da América Hispânica. Seu segundo romance, El caminho de El Dorado (1947), mais que um romance, configura uma biografia narrada do conquistador Lope de Aguirre e uma espécie de geografia poetizada. Como bem questiona a investigadora chilena Ana Pizarro, em seu livro Amazonía: El río tiene voces:

\begin{abstract}
¿Quién es Lope de Aguirre? ¿Quién es este expedicionario de rebeldía histórica que penetró por el Marañón hasta la confluencia con el Ucayali, siguió por el gran río hasta llegar al Atlántico, alcanzó en el Caribe a la Isla Margarita, en donde su paso marcó una época de terror, y, queriendo llegar a Panamá para atravesar el istmo, se vio obligado a tomar la vía de Valencia, para terminar muerto en Barquisimeto? Vilipendiado por unos y glorificado por otros, la figura de Lope de Aguirre es una de las pocas que aparece con tanta riqueza de entre los llamados descubridores, los primeros europeos que abrieron a los ojos del mundo del que procedían el espacio americano, a través de sus informes, cartas y memoriales. Aguirre fue, como tantos otros, justificadamente tildado de asesino: no lo hizo más que otros, sólo que lo hizo con determinación explícita y desfachatez. A la luz de los siglos, esta actitud aparece atractiva en el personaje, frente al solapamiento con que actuaban los demás, los que realizaron actos vandálicos similares y sustentaron de igual modo su poder (PIZARRO, 2009, p. 46).
\end{abstract}

Durante dez intermináveis meses se cumpre a alucinante travessia ao longo do rio Amazonas, que constitui não um mero cenário geográfico no romance, mas uma presença vital. A fome e as febres tropicais vão dizimando, pouco a pouco, a tropa, mas, sobretudo, as intrigas e o ódio convertem em um verdadeiro pesadelo o lento avanço das frágeis embarcações. Lope de Aguirre, integrante da expedição de Pedro de Ursúa, elimina progressivamente seus antecessores, e, em certo ponto da narrativa, torna-se dono da situação e figura central a partir da qual toda a ação do romance se desenvolverá.

A expedição chega à Ilha Margarida, na costa venezuelana, e prosseguem cometendo brutalidades contra a vida e os bens do aterrorizado povo da ilha. Logo a fama das sinistras façanhas, atribuídas a Lope de Aguirre, se propaga por toda a região e, quando desembocam em terra firme, em Nossa Senhora da Conceição da Burburata, encontram um povo completamente deserto.

A busca pelo El dorado sintetiza a busca pelo lugar de todas as riquezas. Como se pode ver neste trecho da obra El camino de El Dorado: "-Vamos derechos a El 
Dorado, mis amigos. Este es el preciso camino que han señalado los indios brasiles. Es tanto el oro que allí se encuentra que uno anda como deslumbrado, casi sin poder abrir los ojos, como lechuza al mediodía" (USLAR PIETRI, 1956, p. 199).

A tropa de navegação espanhola estava entregue ao azar e suas consequências:

Todo era extraordinario y desconocido. Pero no parecían sentir gran sorpresa ante aquel mundo de la vida del río inmenso. Era como si lo vieran de lejos y con despego, buscando otra cosa. Parecían, además, fríamente entregados al azar y a sus consecuencias. [...] De una a otra embarcación se hablaban poco y a gritos para transmitirse informaciones, preguntar por los enfermos o consultarse sobre el rumbo. Después volvían largos espacios de silencioso deslizarse sobre el agua, mientras el sol subía y un húmedo calor envolvía los cuerpos (USLAR PIETRI, 1956, p. 217-218).

\section{O rio Amazonas embalava a busca dos corpos espanhóis pelo mistério em torno}

da atraente, temerosa e desconhecida selva com seus rios, animais e ruídos:

[...] los hombres sentían la avasalladora presencia de lo desmesurado y de lo misterioso. Era el mundo infinito de aquella agua viva que se multiplicaba en el cauce inmenso y que rodaba, con sus troncos, con sus animales, con sus ruidos hacia un rumbo desconocido, que nadie podía modificar. Y era también el mundo infinito de la selva espesa, impenetrable y desconocida llena de una vida huraña, pulutante y temible. Esa presencia los rodeaba, con aspectos cambiantes, en todas las horas y en todos los sitios. Nunca llegaban a sentirse solos, y nunca llegaban a sentirse confiados y tranquilos (USLAR PIETRI, 1956, p. 220).

A fome, a peste e a fúria imperiosa da natureza os tornavam reticentes quanto à existência do El Dorado, mas o afã pela fama e riqueza que os esperavam no lugar da plenitude de todas as necessidades lhes incitava a seguir adiante:

No tenían motivo para aquella alegría, pero todos sentían una profunda necesidad de cambiar, aunque fuera por un momento, el tono y el dramático color que habían ido tomando sus vidas. Aquella larga sucesión de días y días sobre el río sin límites y de noches sobresaltadas, rumiando en el desvelo su angustiosa desesperanza. [...] Pero nada de eso podía hacerles olvidar lo que en el fondo de cada quien estaba royéndole el sosiego: la inutilidad de todos los esfuerzos hechos para encontrar el reino de El Dorado y la poca esperanza que quedaba de hallarlo (USLAR PIETRI, 1956, p. 240-241).

Com o assassinato do governador Pedro de Ursúa, Lope de Aguirre logra a tomada de poder. Há um deslocamento da centralidade do romance em torno do percurso do rio rumo ao El Dorado para a figura de Lope de Aguirre e suas artimanhas:

Desde la noche del asesinato de Ursúa las cosas parecían haberse desarrollado con una velocidad vertiginosa. Los que antes eran lentos días de agotadora espera, se habían trocado ahora en acelerada sucesión de emociones y sucesos. Los terribles acontecimientos y sus variadas consecuencias parecían haber borrado un poco la presencia, hasta entonces avasalladora, del mundo natural. Ya no era la vastedad letal de la selva, ya no era el temor de las mil formas de la muerte desconocida que acechaban al soldado en aquellas soledades. Ahora, lo que fijaba la atención de todos, era la cadena de sucesos que habían venido ocurriendo desde aquella noche. La honda sensación de maleficio y de fatalidad que durante la larga jornada había venido penetrándolos a todos, como una de aquellas densas nieblas que 
se alzaban en la madrugada del río, había venido a concentrarse ahora en los hechos y los rostros de los hombres de la expedición. Aun el ansia de llegar el reino de El Dorado parecía haberse apagado. Algo, más dramático y próximo, se había interpuesto (USLAR PIETRI, 1956, p. 255).

Nas palavras de Lope de Aguirre, na obra de Uslar Pietri:

Y caminando nuestra derrota, pasando todas estas muertes y malas venturas en este río Marañón, tardamos hasta la boca de él y hasta la mar más de diez meses y medio: caminamos cien jornadas justas, anduvimos mil quinientas leguas. Es río grande y temeroso... Tanto andado y tanto por andar todavía. ¿Cuándo habría de descansar? Estaba en guerra contra el rey, en guerra contra la naturaleza, en guerra contra sus mismos hombres. ¿Cuántos marañones más habrían de traicionarlo? (USLAR PIETRI, 1956, p. 371)

Ainda, conforme o personagem:

Tan grandes son nuestras maldades que, podéis tener por cierto, que ni en España, ni en las Indias, ni en parte ninguna, que hayamos oído, ha habido hombres que las hayan hecho más grandes. [...] Ni os perdonará el rey, ni os perdonará el verdugo, ni podrán perdonaros los parientes y amigos de todos los que habéis muerto, que os habrán de perseguir mientras alienten hasta que logren quitaros las vidas y así no tendréis sosiego y viviréis corridos y afrentados, sin que haya estanciero ni calpiste, que no os vitupere y baldone con nombre de tiranos, hasta que al fin hayáis de morir de malas muertes. [...] Además si ahora pasamos trabajos y hambres, mañana tendremos descanso y hartura, como unos mismos reyes, cuando lleguemos a Perú (USLAR PIETRI, 1956, p. 385-386).

Lope de Aguirre morre pelas mãos de seus próprios soldados, que se unem ao exército inimigo, em uma tentativa desesperada e bem-sucedida de libertar-se do tirano. A obra El camino de El Dorado é mais que um relato da história da Conquista, mais que uma narrativa do descobrimento espanhol do Rio Amazonas, mais que uma narrativa do imaginário mítico europeu. A busca pelo El Dorado, empreendida em 1559, configura uma traição à monarquia, um rompimento com o reinado de Felipe II, um início de processo de independência, tão bem registrado pelas cartas-manifestos destinadas ao rei da Espanha, nas quais Lope de Aguirre declarava sua independência e a de seu grupo de "marrañones".

Aguirre se propunha a levar sua "doutrina" ao Peru, atravessar o rio Amazonas, chegar ao Caribe e terminar no Panamá, a fim de liberar o continente do jugo espanhol. Se não pudesse fazê-lo, ao menos sua fama ficaria registrada na memória da humanidade para sempre. O motivo de sua empreitada é, sobretudo, político. Trata-se de um jogo de poder, de um princípio separatista, liberador da coroa espanhola. Parece algo demencial a atitude de Aguirre, ao escrever as rebeldes cartas, se considerada a época de rigidez monárquica, mas esta, no fundo, marca um princípio histórico com a consignação de uma nova ordem. 
Uslar Pietri compreende, com maestria, o diálogo que a sociedade exerce com o território usado. Conforme apontado pelo geógrafo brasileiro Milton Santos (2001), em seu livro Território e Sociedade: entrevista com Milton Santos, território exerce um diálogo que inclui tanto o natural quanto o artificial, tanto a herança social quanto a sociedade em seu movimento atual.

Cada ação social, na visão de Santos (2001), apropriada para a análise da obra de Uslar Pietri (1956), inclui a Terra e os seres que a habitam, e cada situação seria outra, em caso de que fosse outro, também, o território e seu uso, ou seja, há uma relação de dependência mútua entre os mesmos. Milton Santos (2001) adverte para que, como estamos acostumados a pensar a história como se esta se configurasse a partir da relação direta dos homens com a Terra, quando, na verdade, tal relação está perpassada tanto pela intermediação das heranças sociais e materiais quanto pelo presente social ${ }^{2}$.

Arturo Uslar Pietri constrói romances que revisitam o passado como uma forma de sacudir o presente. Seu objetivo é oferecer a seu país, de passado modesto, com possibilidades até então limitadas, a possibilidade de ser uma nova Venezuela. Expressa sua intenção quando escreve a obra Letras y hombres de Venezuela, em 1948, na qual o escritor se dedica inteiramente a contribuir para a formação da cidadania venezuelana, refletindo, como o próprio título sugere, sobre a realidade da Venezuela, desde a sua Conquista, avançando para a figura de Simon Bolívar e seguindo na reflexão sobre a representação social de outros escritores e intelectuais como Andrés Bello, Juan Vicente González, Cecilio Acosta, Pérez Bonalde, os quais o autor define como "servidores del espíritu de los pueblos americanos y de la civilización”, culminando, finalmente, com outra reflexão sobre o romance e o conto venezuelano.

Ainda nesta obra, a respeito do romance venezuelano, Uslar Pietri realiza duas defesas polêmicas:

La novela hispano-americana es hoy la más importante de lengua española; y, dentro de ella, ninguna aventaja a la novela venezolana. Ningún país hispanoamericano excede a Venezuela en la numerosa, continuada y creadora familia de novelistas que posee, que en el último medio siglo ha contado con más de quince novelistas importantes, que han escrito una cincuentena de novelas notables, muchas de las cuales habrán de quedar en la historia de la literatura continental. Venezuela, que durante el siglo XIX había producido algunas grandes figuras literarias, las más de ellas aisladas e inconclusas, va a tener en la novela, y en la literatura de ficción en general, el más grande florecimiento de su literatura. Ya no se trata de grandes nombres dispersos, sino de un movimiento de conjunto, que cubre generaciones sucesivas, que cobra vigor social y sentido nacional, y que afirma, a través de sus variadas creaciones, rasgos propios. Ya se puede subir al mirador del género y mirar en conjunto armónico a los individuos que lo cultivan (USLAR PIETRI, 1956, p. 1045-1046). 
Segundo Uslar Pietri, há vigor, há ânsia criadora, há vida no romance venezuelano. Sem este, o rosto de seu país estaria incompleto e muito de seu mistério não haveria começado a expressar-se. Não há, de acordo com o autor, manifestação mais alta de poder e espontaneidade em nenhuma outra forma literária.

Em De una a otra Venezuela, escrita em 1949, Uslar Pietri dizia-se movido por um sentimento de angústia quanto aos acontecimentos dramáticos ocorridos na vida venezuelana, ocasionados pela grande crise que atravessava o país. Crise esta, que se reflete na vida política, econômica e social. Crise de transformação e deformação fundamentalmente econômica que se complica no político e repercute no social. A origem está na crise do petróleo e, a partir do mesmo, o escritor discute a educação, a economia e a sociedade.

Sua obra é uma evocação ao povo venezuelano para implicar-se nas mudanças de seu país, dividido em uma grande maioria pobre e desinformada e uma minoria das modernas cidades que recebe os benefícios monetários da riqueza petrolífera. Nas palavras de Uslar Pietri:

De unas a otras, de una a otra Venezuela debe ir la angustia creadora de los venezolanos. De una a otra Venezuela, de la que no es a la que debe ser, ha de encaminarse la acción colectiva. Lo que no es otra cosa que invocar una política venezolana para un país que casi no la ha conocido. Hay que salvar a Venezuela. Nadie es tan fuerte que pueda salvarla solo, ante la indiferencia de los demás. Nadie es tan pequeño o insignificante que pueda negar su esfuerzo sin que el impulso total no se debilite. Es tarea de todos para todos. Yo, por mi parte, nunca he dudado, a pesar de tantos tropiezos, de que los venezolanos seamos capaces de semejante empresa. Porque no lo dudo he escrito las palabras que están en este libro, y en él las recojo para lanzarlas como un pedrusco a la campana que ha de despertar al pueblo venezolano, mi pueblo (USLAR PIETRI, 1956, p. 1345).

A vida de um povo consiste em uma perpétua crise de crescimento e adaptação a circunstâncias constantemente mutáveis. Tal realidade é a razão pela qual a política e o governo tornam-se arte complexa. Arte esta, muito mais complexa do que supõem os demagogos de praça pública. Quando um povo assume consciência de sua missão, de seu caminho, de seu básico e permanente interesse, pode subordinar todas as circunstâncias a estes fins superiores, de modo a ascender no caminho da história. Ainda nas palavras de Uslar Pietri:

En algunas épocas, los hombres se han matado entre sí porque entendían de distinta manera el amor de Dios. Este horrible absurdo de matar a la criatura por amor del Creador fue posible porque el tono pasional en que se desarrolló la pugna religiosa hizo perder de vista los fines verdaderos y superiores. No sería menos absurdo que nos hubiéramos de odiar porque entendemos de modo distinto el amor de Venezuela. El verdadero amor de Venezuela, por el 
contrario, es lo que debe acercarnos a todos los que lo sentimos y empequeñecer nuestras divergencias (USLAR PIETRI, 1956, p. 1463).

Uslar Pietri, em sua obra En busca del nuevo mundo, trata da questão da identidade dos povos hispano-americanos, a partir do tema da mestiçagem cultural. Discute a busca do homem americano em si próprio, entre contraditórias heranças e dissímiles parentescos, que o levam a atuar ora como ser desterrado em sua própria terra, ora como conquistador desta:

Por un absurdo y antihistórico concepto de pureza, los hispanoamericanos han tendido a mirar como una marca de inferioridad la condición de su mestizaje. Han llegado a creer que no hay otro mestizaje que el de la sangre y se han inhibido en buena parte para mirar y comprender lo más valioso y original de su propia condición. Se miró al mestizaje como un indeseable rasgo de inferioridad. Se estaba bajo la influencia de las ideas de superioridad racial desde el siglo XVIII y se afirmaron en el XIX con Gobineau, que dieron nacimiento a toda aquella banal literatura sobre la supremacía de los anglosajones y sobre la misión providencial y el fardo histórico del hombre blanco encargado de civilizar, dirigir y encaminar a sus inferiores hermanos de color. Se creó una especie de complejo de inferioridad y de pudor biológico ante el hecho del mestizaje sanguíneo. Se quería ocultar la huella de la sangre mezclada o hacerla olvidar ante los europeos, olvidándonos de que Europa era el fruto de las más increíbles mezcolanzas y de que el mestizaje de sangre podía ser un efecto, pero estaba lejos de ser la única causa ni la única forma de mestizaje cultural. Lo verdaderamente importante y significativo fue el encuentro de hombres de distintas culturas en el sorprendente escenario de la América. Ése y no otro es el hecho definidor del Nuevo Mundo (USLAR PIETRI, 1969, p. 13).

As ideias ocidentais invadem a América rumo a um novo destino, rumo a uma mescla cultural originária de novas significações, cujos sentidos dão-se na lenta e contrastada fissura dos povos americanos. O Descobrimento da América transformouse, para a Europa, no descobrimento da Utopia, propiciado pelo contato com as culturas indígenas ricas em teogonias, mitos, lendas e crenças. Para a América, por sua vez, o contato com europeus incorpora a maneira de ser e entender advinda da Antiguidade greco-latina e hebreia; incorpora a herança de livros, filosofia e herança teológica da Idade Média. Conforme as palavras de Uslar Pietri:

El modernismo no es un episodio aislado, su voluntad de mezcla y de incorporación aluvional sigue activa en el desarrollo ulterior de la literatura de la América Hispana. Las grandes novelas americanas de la tercera década del siglo expresan esa impureza receptiva en su poderosa combinación de realismo, costumbrismo, simbología, forma épica y trasfondo mágico. ¿A qué época o a qué escuela europea podrían asimilarse Gallegos, Guiraldes, Rivera, Azuela? La poesía de Gabriela Mistral es una trémula confluencia de tiempos y modos. El aire barroco que mueve las frases de Asturias y Carpentier está mezclado con elementos románticos, con sabiduría surrealista y con la atracción por la magia de los pueblos primitivos. Un libro como Los pasos perdidos o como El señor presidente refleja, en el más mestizo lenguaje creador, el mestizaje original y profundo del Nuevo Mundo. Jorge Luis Borges es el más refinado manipulador de la vocación y de los elementos del mestizaje cultural. La torrencial voracidad transformadora y caótica de Pablo 
Neruda tiene sus raíces y su razón en el poderoso fenómeno del mestizaje americano. No solo hay una vocación de superponer influencias y escuelas sino que, además, hay una deformadora capacidad de asimilar y desnaturalizar las influencias, que no es otra cosa que la avasallante consecuencia cultural del hecho americano (USLAR PIETRI, 1969, p. 23).

Para Arturo Uslar Pietri, a América Hispânica é, talvez, a única grande zona aberta no mundo do século XX ao processo de mestiçagem cultural criador. Ao invés de considerar tal característica extraordinária como uma marca de atraso ou de inferioridade, faz-se mister enxergá-la como a mais afortunada e favorável circunstância para a compreensão da personalidade fecunda e poderosa da América Hispânica, bem como de sua originalidade e tarefa criadora. Sobre a América Latina, no século XXI, Uslar Pietri defende que:

Su vocación y su oportunidad es la de realizar la nueva etapa de mestizaje cultural que va a ser la de su hora en la historia de la cultura. Todo lo que se aparte de eso será desviar a la América Latina de su vía natural y negarle su destino manifiesto, que no es otro que el de realizar en plenitud la promesa de los Garcilaso, de los Bolívar, de los Darío, de los constructores de catedrales, para la obra de un Nuevo Mundo (USLAR PIETRI, 1969, p. 26).

La creación del Nuevo Mundo representa a maturidade das reflexões que Uslar Pietri (1991) vinha desenvolvendo, ao longo de toda sua carreira, no que diz respeito à originalidade cultural da América Hispânica, sua busca multicentenária por identidade, seu contraditório passado, seu difícil presente e as vias possíveis de seu porvir. Como Octavio Paz já elucidara o autor venezuelano, igualmente, crê que a tentativa de “desviver a própria história" é o cerne do trágico equívoco da história política da América Latina. Há que se considerar a excentricidade desta, ou seja, sua não correspondência com os movimentos e características do cêntrico modelo europeu.

$\mathrm{Na}$ insurgência da América Latina, o pensamento é questionador, crítico e reformador; os romances são de protesto e luta contra a ordem recebida. O anseio é por alguma forma efetiva e imediata de mudança do presente. Invocam-se, para tanto, princípios e doutrinas, recentes ou antigas, vindas de fora, mas que se mesclam com a mitologia local e a realidade existencial. Mais que um pensamento crítico ao estilo da Europa, constrói-se na América Latina uma espécie de pregação missionária. A atitude é de tentativa de levar uma salvação que se propague e salve os povos americanos da complexidade de sua história.

Uslar Pietri questiona, com maestria, o seguinte:

La cuestión verdadera no consiste en preguntarse si la literatura de la América Latina es o no moderna, lo cual implica una comparación con un modelo más o menos arbitrario y ajeno, constituido generalmente por la última literatura que hacen en Londres, en París o en Nueva York, sino la de 
preguntarnos si es o no hispanoamericana, si expresa o no la peculiar y única circunstancia del hombre hispanoamericano y su situación histórica y cultural (USLAR PIETRI, 1991, p. 153).

Esta grande experiência de encontros de culturas que teve como cenário o mundo americano, através da linguagem, dos usos e das experiências, veio a converterse em uma nova dimensão de toda a comunidade hispânica. Não houve em toda a história uma experiência de tamanha envergadura e consequências. O contato estreito, durante séculos, entre o europeu, o índio e o negro, as "protocélulas" formadoras do povo latino-americano, gerou não apenas consequências sociais e culturais, mas também uma nova concepção de mundo e de humanidade (RIBEIRO, 1986) ${ }^{3}$. Como bem diria o escritor venezuelano Simón Rodríguez “A América Latina é original, portanto não deve copiar" ${ }^{\prime}$. Em concordância com tal premissa, Uslar Pietri retoma uma vez mais a perspectiva do autor e conclui: "o inventamos, o erramos".

A obra de Uslar Pietri é um convite aberto à aceitação de nossas raízes, em sua riqueza histórica, culminantes em uma mestiçagem cultural que nos garante uma forma bastante única de sermos ocidentais, como se verifica a seguir:

\begin{abstract}
Nadie puede negar hoy que todos los iberoamericanos formamos evidentemente una extensa y varia comunidad hecha por la historia y por la geografía, que es distinta a todos y cada uno de sus componentes y que por ello mismo tiene una inescapable condición de originalidad. Somos lo que la historia nos ha hecho, más allá de polémicas y de complejos de culpabilidad, somos la herencia viva de cinco siglos de creación histórica que han formado una realidad autónoma y poderosa que es la nuestra y la única de la que podemos partir para avanzar hacia el porvenir que nos está ofrecido. No podemos detenernos y desviarnos en una estéril disputa, casi teológica, sobre el pecado original del que hemos nacido, o en declararnos partidarios de uno de nuestros abuelos contra otros de ellos mismos. Lo que importa es que somos como somos y todo lo que podemos hacer tiene que partir de esa certidumbre (USLAR PIETRI, 1991, p. 186).
\end{abstract}

Em nossa mestiçagem cultural reside nossa contradição e singularidade. Em nossa latinidade ocidental, proveniente do Pecado original da Conquista, reside nossa descendência, herança e futuro. Para o século XXI, em seus desafios transnacionais, cabe a compreensão, ainda que tardia, desta base cultural histórica latino-americana para que, enfim, alcancemos a maturidade crítica necessária para a percepção e análise das questões transculturais deste tempo presente.

\title{
Referências
}

LUKÁCS, Georg. A teoria do romance: um ensaio histórico-filosófico sobre as formas da grande épica. Trad. posfácio e notas de José Marcos M. de Macedo. SP: Duas Cidades; Ed. 34, 2000. 
MENESES, Guillermo. Cuento de Venezuela. Pref. A. Uslar Pietri. Caracas: Tamanaco, 1960.

PESSOA, Fernando. Obras poéticas. Rio de Janeiro: Nova Aguilar, 1974.

PIZARRO, Ana. Amazonía: El río tiene voces. Chile: Fondo de Cultura Económica, 2009.

RAMA, Ángel. Transculturación narrativa en América Latina. $2^{\mathrm{a}}$ ed. Buenos Aires: El Andariego, 2008.

RIBEIRO, Darcy. América Latina: a pátria grande. Rio de Janeiro: Guanabara Dois, 1986.

SANTOS, Milton. Território e Sociedade: entrevista com Milton Santos. SP: Fundação Perseu Abramo, 2001.

USLAR PIETRI, Arturo. En busca del nuevo mundo. México: FCE, 1969.

. Ensayos sobre el nuevo mundo: antología de textos políticos. Introducción y selección de Agapito Maestre. Madrid: Editorial Tecnos, 2002.

La creación del nuevo mundo. México: Fondo de Cultura Económica, 1991.

Las lanzas coloradas. El camino de El Dorado. Barrabas y otros relatos. Red (cuentos). Treinta hombres y sus Sombras. Las visiones del camino. La ciudad de nadie. El otoño en Europa. Un turista en el cercano oriente. Letras y hombres de Venezuela. Apuntes para retratos. Las nubes. De una a otra Venezuela. In: Obras Selectas. Madrid, Caracas: Edime, 1956.

\footnotetext{
Notas:

1 "Restablecer las obras literarias dentro de las operaciones culturales que cumplen las sociedades americanas, reconociendo sus audaces construcciones significativas y el ingente esfuerzo por manejar auténticamente los lenguajes simbólicos desarrollados por los hombres americanos, es un modo de reforzar estos vertebrales conceptos de independencia, originalidad, representatividad. Las obras literarias no están fuera de las culturas sino que las coronan y en la medida en que estas culturas son invenciones seculares y multitudinarias hacen del escritor un productor que trabaja con las obras de innumerables hombres. Un compilador, hubiera dicho Roa Bastos. El genial tejedor, en el vasto taller histórico de la sociedad americana." [Tradução nossa]

${ }^{2}$ O geógrafo Milton Santos estabelece a seguinte definição para o conceito de território, pertinente para o nosso estudo: "o território em si, para mim, não é um conceito. Ele só se torna um conceito utilizável para a análise social quando o consideramos a partir do seu uso, a partir do momento em que o pensamos juntamente com aqueles atores que dele se utilizam”. In: SANTOS (2001) p.22. Apoiamo-nos, assim, para esta pesquisa, na definição de território exposta acima, atribuída pelo respectivo autor.

${ }^{3}$ O antropólogo brasileiro Darcy Ribeiro aborda, em sua obra, a concepção de um novo gênero humano, como fruto do choque entre índios, negros e europeus, "protocélulas" formadoras do povo latinoamericano, em consonância com a perspectiva defendida por outros escritores como Simón Rodríguez e José Martí. Cf. RIBEIRO (1986).
} 
A (re)construção de identidades do ser americano moderno e a criação simbólica de Arturo Uslar Pietri: diálogos entre literatura e história | Gisele Reinaldo da Silva

4 “La América Latina es original, por lo tanto no debe copiar”. In: USLAR PIETRI (1991) p.178. [Tradução nossa]

[Recebido: 21 set. 2014 / Aceito: 06 nov. 2014] 